\title{
O lugar das crianças nos debates sobre políticas públicas para a cidade: uma análise dos programas de candidatos à prefeitura do Rio de Janeiro em 2016
}

The children's place in the debates over public policies for the city: an analysis of candidate programs for Rio de Janeiro City Hall in 2016

El lugar de los niños en los debates sobre políticas públicas para la ciudad: una análisis de los programas de candidatos a la alcaldía de Río de Janeiro en 2016

Ligia MARIA LEÃo DE AQUINO*

$\diamond$

\begin{abstract}
RESUMO
O artigo visa a discutir o tema sobre direitos e políticas públicas na cidade na relação com a infância, analisando programas dos candidatos à prefeitura do Rio de Janeiro no ano de 2016 e indagando sobre o lugar das crianças nos planos de governo dos 11 candidatos ao cargo de prefeito da cidade do Rio de Janeiro, para a gestão de 2017-2020. A reflexão sobre direitos e políticas públicas na cidade, a partir do olhar das crianças, fez-se em um exercício de buscar as suas perspectivas, não em suas falas ou manifestações, mas pela compreensão de infância como potência, entendendo ser possível estudar a infância por meio dela mesma ao assumir um movimento de interpretação do material investigado com "olhos de criança". Não se trata de retornar à infância, mas de adotar uma compreensão de infância e das crianças na condição de sujeitos ativos, atores sociais e culturais. A análise realizada evidenciou o quanto ainda é necessário investir e disputar na produção de discurso que afirme o lugar das crianças como cidadãos de direitos, direitos fundamentais à pessoa.
\end{abstract}

Palavras-chave: Infância e cidade. Políticas públicas para a infância. Rio de Janeiro. Programas de governo.

Abstract

The article aims to discuss the theme of rights and public policies in the city towards to childhood, analyzing candidates' programs for the Rio de Janeiro City Hal in 2016, wondering about the place of children in the government programs of the eleven candidates for the City of Rio de Janeiro Mayor, on the term of 2017-2020. The reflection on rights and public policies in the city from the children's perspective as an exercise of such perspective, not through their speeches or manifestations, but through the understanding of childhood as a power, understanding that it is possible to study childhood through itself and assuming a movement of interpretation of the material investigated with the children's look. It is not a matter of returning to childhood, but of adopting an understanding of childhood and children as active and cultural subjects, as social actors themselves. The analysis made clear how much more it is necessary to invest and negotiate in a discourse production which affirms the children's place as subjects of rights, the fundamental rights to the person.

Keywords: Childhood and city. Public policies for children. Rio de Janeiro. Government programs.

\section{RESUMEN}

El artículo discute el tema acerca de los derechos y políticas públicas de la ciudad en su relación con la infancia analizando programas de los candidatos a la alcaldía de Río de Janeiro, en el año 2016, indagando sobre el lugar de los niños en los programas de gobierno de los once candidatos al cargo de alcalde de Río de Janeiro, para la gestión de 2017-2020. La reflexión sobre los derechos y políticas públicas en la ciudad desde la mirada de los niños se hizo en un ejercicio de búsqueda hacia la perspectiva de los niños y no a través de sus palabras o manifestaciones, sino por la comprensión de la niñez como potencia, entendiendo así que es posible estudiar la niñez a través de ella misma al pensar un movimiento de interpretación del material investigado, con los ojos mismos de los niños. Que no se trata de regresar a la infancia, sino adoptar una comprensión de infancia y de los niños en la condición de sujetos activos y culturales o sea, actores sociales. El análisis realizado evidenció cuánto aún es necesario invertir y negociar en la producción del discurso que afirme el lugar de los niños como sujetos de derechos, que son derechos fundamentales a la persona. Palabras clave: Infancia y ciudad. Políticas públicas para la infancia. Rio de Janeiro. Programas de gobierno.

\footnotetext{
* Professora associada da Faculdade de Educação e do Programa de Pós-Graduação em Educação da Universidade do Estado do Rio de Janeiro (Uerj). Coordenadora do Grupo de Pesquisa Infância e Saber Docente e integrante do Núcleo de Estudos da Infância: Pesquisa e Extensão (Neipe/Uerj). $<$ https://orcid.org/0000-0002-8767-7203>. E-mail: <ligiaaquino@yahoo.com.br>.
} 


\section{INTRODUÇÃO}

O trabalho que ora apresentamos busca discutir o tema proposto - direitos e políticas públicas na cidade na relação com a infância, analisando os programas dos candidatos à prefeitura da cidade do Rio de Janeiro em 2016. O exercício de visitar esses programas nos fez compreender que tais documentos são discursos produzidos (e produtores) de projetos societários. São portadores de verdades assumidas por quem as proclama, considerados do agrado da população ou do agrado de parcela do eleitorado que os candidatos desejam conquistar para vencer a disputa eleitoral. De qualquer forma, esses documentos expressam e fazem circular verdades produzidas socialmente. Em uma campanha política para cargo majoritário, temos a oportunidade de observar os projetos de sociedade em disputa e aquilo que se considera como de grande interesse da população em geral, aferido a partir de pesquisas de opinião e matérias de impacto na mídia.

De outra parte, entendemos que pensar a relação crianças-cidade implica tomar o conceito de território para além do sentido de "uma dimensão de terra" e reconhecer o "[...] conjunto de forças e dinâmicas que nele operam" (SPOSITO, apud ARAÚJO, 2011, p.139). Esse conceito, como afirma Araújo (p.139), permite relativizar "[...] a perspectiva universalizante das ações comumente adotadas [ao considerar que a] [...] realidade territorial pressupõe singularidades, subjetividades" (p. 139).

Esta questão nos ajuda a compreender que a medida orientadora das políticas públicas deve ser as condições reais de vida dos sujeitos, condições essas que expõem fragilidades, as desigualdades sociais, a ruptura de vínculos sociais, simbólicos e materializados, mas também a potência dos diferentes grupos (ARAÚJO, 2011, p. 139).

Nesse sentido, indagamos: como as crianças, um dos diferentes grupos que compõem a vida da cidade, estão presentes no debate sobre políticas públicas para a municipalidade? Sabemos que a criança tem ganhado espaço na sociedade contemporânea. No campo acadêmico, é objeto de investigação e problema para diversas áreas de intervenção, como a educação e a saúde. No campo econômico, cada vez mais a criança é identificada como consumidora, destinatária de serviços e também tratada como objeto de forte apelo para seduzir consumidores (agora dividindo esse lugar com os animaizinhos domésticos - pets). Não podemos esquecer ainda o espaço alargado da presença da criança na esfera jurídica, com um conjunto de documentos e legislação ${ }^{1}$

\footnotetext{
1 No Brasil, tem-se como grande marco o Estatuto da Criança e do Adolescente, instituído pela Lei Federal no 8.069, de 13 de julho de 1990, aprovada quatro meses antes do Decreto no 99.710 , de 21 de novembro do mesmo ano, que promulgou a Convenção sobre os Direitos das Crianças, documento aprovado em 20 de novembro de 1990 pela Assembleia Geral das Nações Unidas (ONU).
}

que asseguram direitos e estabelecem normas de condutas, numa relação que oscila entre tutela e liberdade. Além disso, os direitos garantidos formalmente não significam, como lembra Araújo (2011, p. 137), “[...] a visibilidade pública do outro como sujeito produtor de sentidos para a cidade".

Desse pressuposto, nos dispusemos indagar sobre o lugar das crianças nos programas de governo dos 11 candidatos ao cargo de prefeito da cidade do Rio de Janeiro.

\section{OS PROGRAMAS DE GOVERNO DOS CANDIDATOS À PREFEITURA DO RIO DE JANEIRO EM 2016}

As candidaturas desse pleito abarcaram uma variedade de partidos e tendências político-ideológicas, da esquerda à direita, de antigos a novos partidos, de viés mais ideológico a caráter mais fisiologista. Os programas evidenciavam essas marcas e também variavam nas suas formulações, umas mais elaboradas ou simplistas na apresentação de análise da máquina pública, do papel do Estado, na definição de áreas prioritárias, nos objetivos, metas e estratégias. Assim, encontramos documentos de duas até 110 páginas. Para se ter uma ideia da estrutura, temáticas e abordagens dos programas, trazemos os sumários de três documentos. O primeiro é do candidato Pedro Paulo $\left(\mathrm{PMDB}^{2}\right)$, vinculado ao prefeito à época (Eduardo Paes, então do mesmo partido), que foi derrotado ainda no primeiro turno; o segundo sumário é do documento do candidato Marcelo Crivella $\left(\mathrm{PRB}^{3}\right)$, que venceu as eleições no segundo turno; e o terceiro é do candidato Marcelo Freixo (PSOL ${ }^{4}$ ), que disputou o segundo turno.

Quadro 1. Sumário do Programa de Governo do Candidato Pedro Paulo (RJ, 2016)

\begin{tabular}{|c|}
\hline $\begin{array}{l}\text { Pedro Paulo - PMDB, PDT }{ }^{\mathrm{a}}, \mathrm{PP}^{\mathrm{b}}, \mathrm{PTB}^{\mathrm{c}}, \mathrm{PSL}^{\mathrm{d}}, \mathrm{SD}^{\mathrm{e}}, \mathrm{DEM}^{\mathrm{f}} \text {, } \\
\text { PROS }^{\mathrm{g}}, \mathrm{PHS}^{\mathrm{h}}, \mathrm{PMN}^{\mathrm{i}}, \mathrm{PEN}^{\mathrm{j}}, \mathrm{PSDC}^{\mathrm{k}}, \mathrm{PTC}^{\mathrm{l}}, \mathrm{PT}^{\mathrm{do}} \mathrm{B}^{\mathrm{m}}, \mathrm{PRTB}^{\mathrm{n}}\end{array}$ \\
\hline Alto valor humano: equidade de oportunidades e cidadania \\
\hline Rio de Janeiro: fonte de bem-estar, qualidade de vida e dignidade \\
\hline Cidade verde, sustentável e resiliente \\
\hline Território conectado, integrado e democrático \\
\hline Cidade competitiva, inovadora e de oportunidades \\
\hline Governança e reinvenção sustentável da máquina pública \\
\hline
\end{tabular}

a Partido Democrático Trabalhista; ${ }^{\mathrm{b}}$ Partido Progressista; ${ }^{\mathrm{c}}$ Partido Trabalhista Brasileiro; ${ }^{\mathrm{d}}$ Partido Social Liberal; ${ }^{\mathrm{e}}$ Solidariedade; ${ }_{\mathrm{f}}^{\mathrm{f}}$ Democratas; $\mathrm{g}$ Partido Republicano

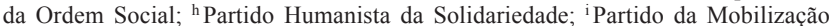

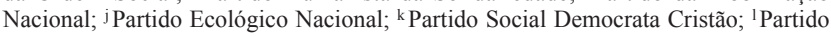
Trabalhista Cristão; ${ }^{\mathrm{m}}$ Partido Trabalhista do Brasil; ${ }^{\mathrm{n}}$ Partido Renovador Trabalhista Brasileiro.

Fonte: Elaborado pela autora com base na Proposta de Governo "\#Chega Junto", da coligação "Juntos pelo Rio".

\footnotetext{
2 Partido Movimento Democrático Brasileiro.

3 Partido Republicano Brasileiro.

4 Partido Socialismo e Liberdade.
} 
Quadro 2. Sumário do Programa de Governo do Candidato Marcelo Crivella (RJ, 2016)

\begin{tabular}{|l|}
\hline Marcelo Crivella - PRB $^{\mathrm{a}}, \mathrm{PR}^{\mathrm{b}}$ e $\mathrm{PTN}^{\mathrm{c}}$ \\
\hline Saúde \\
\hline Educação \\
\hline Segurança e Guarda Municipal \\
\hline Mobilidade urbana \\
\hline $\begin{array}{l}\text { As demais áreas temáticas (máquina estatal, emprego, cultura, } \\
\text { meio ambiente e saneamento) }\end{array}$ \\
\hline
\end{tabular}

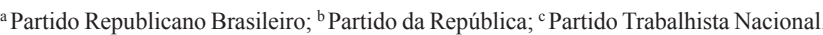
Fonte: Elaborado pela autora com base na Proposta de Governo "Por um Rio mais Humano".

Quadro 3. Sumário do Programa de Governo do Candidato Marcelo Freixo (RJ, 2016)

\begin{tabular}{|l|}
\hline Marcelo Freixo - PSOL ${ }^{\mathrm{a}}$ e $\mathrm{PCB}^{\mathrm{b}}$ \\
\hline Planejamento e gestão: pelo direito à cidade \\
\hline $\begin{array}{l}\text { Justiça socioambiental: ecologia urbana, soberania alimentar e } \\
\text { direito dos animais }\end{array}$ \\
\hline $\begin{array}{l}\text { Trabalho digno e distribuição de renda: direito ao trabalho e } \\
\text { à justiça social }\end{array}$ \\
\hline Moradia: fim das remoções e desenvolvimento comunitário \\
\hline Mobilidade urbana: tarifa zero e integração modal \\
\hline $\begin{array}{l}\text { Saúde: gestão democrática, qualidade no atendimento e } \\
\text { valorização profissional }\end{array}$ \\
\hline $\begin{array}{l}\text { Educação: gestão democrática, autonomia pedagógica e } \\
\text { valorização profissional }\end{array}$ \\
\hline Cultura: além dos espetáculos \\
\hline Assistência social: viver com dignidade \\
\hline Segurança cidadã: pela desmilitarização da cidade \\
\hline Lazer: democratizar o espaço público \\
\hline Esporte: saúde, cultura e paixão \\
\hline
\end{tabular}

a Partido Socialismo e Liberdade; ${ }^{\text {b }}$ Partido Comunista Brasileiro.

Fonte: Elaborado pela autora com base na Proposta de Governo "Mudar é Possível".

Os títulos presentes nos sumários evidenciam as diferenças nos temas priorizados e nas abordagens adotadas. Nos documentos do programa "\#Chega Junto" e "Mudar é Possível", identificamos termos como cidadania/cidadão. Os títulos do sumário do documento "Por um Rio mais Humano" são muito sucintos e não sinalizam a abordagem expressa nos outros dois documentos, enquanto no primeiro documento, "\#Chega Junto", adota-se uma linguagem empresarial, ao nomear "Cidade Competitiva, Inovadora e de Oportunidades". No sumário "Mudar é Possível", predomina uma perspectiva de direitos humanos e compromisso de pautas socialistas, como "Gestão democrática", "Desmilitarização da cidade", "Tarifa zero" e "Direito ao trabalho e à justiça social”.

\section{CRIANÇAS E INFÂNCIAS}

Feita essa primeira leitura, a reflexão sobre o foco do presente artigo - direitos e políticas públicas na cidade a partir do olhar das crianças - se deu em um exercício de buscar a perspectiva das crianças, não em suas falas ou manifestações, mas pela compreensão de infância como potência. Consideramos ser possível "[...] estudar a infância através dela mesma" (SARMENTO; PINTO, 1997), assumindo um movimento de interpretação do material investigado com "olhos de criança", recorrendo à expressão de Francesco Tonucci. ${ }^{5}$ Isto é, não se trata de retornar à infância, mas de adotar uma compreensão de infância e das crianças que afirma a sua condição de sujeitos ativos, de atores sociais e sujeitos culturais (produtores de cultura), o que "[...] permite olhar a infância não mais pela marca da negatividade, da ausência, mas da diferença" (SARMENTO, 2007 apud ARENHART, 2016, p. 44). Assim, buscamos romper com a perspectiva colonizadora e adultocêntrica que toma a criança como sujeito passivo em sua socialização, "sem voz", "sem palavra" (infante), irracional, imaturo, incompetente, imoral, improdutivo, em suma, incompleto e incapaz.

Ainda sobre a relevância de se buscar a perspectiva das crianças, Sarmento e Pinto (1997, p. 125) argumentam que essa concepção contribui para alargar a compreensão da realidade social.

[...] o estudo das crianças a partir de si mesmas permite descortinar uma outra realidade social, que é aquela que emerge das interpretações infantis dos respectivos mundos de vida. O olhar das crianças permite revelar fenômenos sociais que o olhar dos adultos deixa na penumbra ou obscurece totalmente.

A construção desse estatuto social de infante se deu na Modernidade, num movimento que, ao mesmo tempo, reconheceu a infância como categoria geracional, diferenciando-a dos adultos, mas também colocou-a em um lugar de subordinação e de sujeito em falta, por tomar o adulto como referência de ser completo e capaz. E a salvação desse vazio, a razão de existência do infante, é tornar-se adulto (um ideal a ser perseguido), o que se faz via normatividades, prescrições e interdições comuns (ARENHART, 2016). No conjunto de prescrições, a obrigatoriedade escolar expressa o crescente processo de institucionalização da infância e um conjunto de interdições representa a normatividade negativa que se

\footnotetext{
${ }^{5}$ Referência ao título de seu livro Com olhos de criança (1997), o qual ele apresenta com um poema de Gianni Rodari, em que diz: "“[...] Ele me disse, já sou velho, mas veja que coisa linda/De um menininho tenho a orelha ainda/É uma orelha-criança que me ajuda a compreender/O que os grandes não querem mais entender/Ouço a voz de pedras e passarinhos/ Nuvem passando, cascatas e riachinhos/Das conversas de crianças, obscuras ao adulto/Compreendo sem dificuldade o sentido oculto [...]".
} 
atrela à infância: não pode votar, não pode ser eleita, não pode trabalhar. Ainda em Deise Arenhart (2016), que recorre a Sarmento, identificamos que a normatividade negativa, em seu efeito simbólico, é o que define a conceitualização da infância marcada pela exclusão "[...] e não, prioritariamente, por suas características distintivas ou por efetivos direitos participativos" (ARENHART, 2016, p.35).

Sarmento (2007) traz um outro aspecto a se observar na forma como a infância vem sendo apresentada na Contemporaneidade, que é o jogo de visibilidade-invisibilidade produzido nas imagens sociais das crianças e infâncias formuladas na Modernidade.

Historicamente, a infância, como constructo da Modernidade, deu às crianças um lugar distinto e apartado do mundo adulto, ora sendo destinatária de cuidados especiais e de proteção (de ordem física e moral), ora representando estorvo e ameaça ao funcionamento social. A Medicina, como campo de saber hegemônico, desde essa época, vem assumindo o monopólio sobre a infância. Juntamente com a Psicologia, estabeleceu uma rede de conhecimento e controle, normatizando e prescrevendo condutas consideradas próprias para as crianças e para os ambientes a elas destinados. A condição de irracional, imoral, incapaz da criança exige intervenção pedagógica, tornando a escola "lugar de criança", produzindo o "sujeito escolar" e "[...] atribuindo à criança o oficio de aluno $[. .]-$. e a experiência escolar passa a ter sentido pela lógica da integração" (ARENHART, 2016, p. 22).

De outra parte, movimentos libertários, em diversos cantos do mundo e em diferentes contextos, ao ampliarem a compreensão e as pautas de lutas de libertação e afirmação dos direitos humanos, abarcaram também as crianças, reconhecendo-as como sujeito de cultura, social e que se constitui como sujeito de direitos. Tal concepção se observa nos estudos de Florestan Fernandes (2004), na década de 1940, no Brasil; nos escritos de Walter Benjamin (2009, 2015), na Alemanha, sobre diversos aspectos da vida cultural e lugar das crianças na sociedade; ou, ainda, no campo da educação, com o educador francês Celestin Freinet, que apostava nas crianças como sujeitos criativos, expressivos e cooperativos (FREINET, 1979).

Uma série de documentos foi produzida no âmbito internacional e nacional, afirmando a condição da criança como sujeito de direitos. O primeiro documento data de 1959 e foi aprovado em Assembleia da ONU: a Declaração Universal dos Direitos das Crianças. Três décadas mais tarde, produziu-se a Convenção dos Direitos das Crianças (ONU, 1990), em que os "Estados Partes comprometem-se a respeitar e a garantir os direitos previstos na presente Convenção a todas as crianças que se encontrem sujeitas à sua jurisdição". No Brasil, também no ano de 1990, foi promulgada a Lei no 8.069, que dispõe sobre o Estatuto da Criança e Adolescente (ECA) (BRASIL, 1990). O conteúdo do ECA expressa o compromisso da sociedade e do Estado brasileiro com os princípios afirmados nos documentos internacionais mencionados e, de modo sintético, já definidos na Constituição Federal de 1988, no art. 227, o qual estabelece que:

É dever da família, da sociedade e do Estado assegurar à criança, ao adolescente e ao jovem, com absoluta prioridade, o direito à vida, à saúde, à alimentação, à educação, ao lazer, à profissionalização, à cultura, à dignidade, ao respeito, à liberdade e à convivência familiar e comunitária, além de colocá-los a salvo de toda forma de negligência, discriminação, exploração, violência, crueldade e opressão (BRASIL, 1988).

O ECA (BRASIL, 1990), já em seu art. 3o, define a condição e os direitos das crianças e dos adolescentes.

A criança e o adolescente gozam de todos os direitos fundamentais inerentes à pessoa humana, sem prejuízo da proteção integral de que trata esta Lei, assegurando-se-lhes, por lei ou por outros meios, todas as oportunidades e facilidades, a fim de lhes facultar o desenvolvimento físico, mental, moral, espiritual e social, em condições de liberdade e de dignidade (grifo da autora).

Fica expresso que, mesmo a lei reconhecendo a condição da criança como sujeito de proteção integral a ser garantida pela família, pela comunidade e pela sociedade em geral, também visa a lhe garantir a condição de sujeito de direitos, isto é, os mesmos "direitos fundamentais inerentes à pessoa humana". Na estrutura do texto da lei, são apresentados os seguintes Direitos Fundamentais: "Do Direito à Vida e à Saúde; Do Direito à Liberdade, ao Respeito e à Dignidade; Do Direito à Convivência Familiar e Comunitária; Do Direito à Educação, à Cultura, ao Esporte e ao Lazer; Do Direito à Profissionalização e à Proteção no Trabalho" (BRASIL, 1990). Nessa perspectiva, a criança não é apenas objeto de proteção e cuidado, mas sujeito ativo.

\section{AS CRIANÇAS NOS PROGRAMAS DE GOVERNOS}

Tendo essa compreensão da condição legal da criança na sociedade brasileira e considerando as suas condições concretas, cotidianas de vida, buscamos analisar como a criança aparece nos programas de governo, vinculada a que áreas e tipos de ação. Para identificar o lugar das crianças nos 11 programas, localizamos os termos "criança(s)" (complementados com "infância(s)/infantil") nos documentos, observando as áreas de ação política ou serviço e a abordagem adotada sobre a relação das crianças com a cidade e com as políticas públicas. 
Dos 11 programas, um deles não faz qualquer menção à criança e à infância. ${ }^{6} \mathrm{Em}$ um outro programa, o termo "criança" aparece 34 vezes, ressaltando que, nesse caso, trata-se de documento mais extenso, ${ }^{7}$ com 110 páginas, e que traz uma redação em que se repetem assuntos ao longo do texto, estruturado com um sumário geral. Em cada tópico temático, há subdivisão com os seguintes elementos: apresentação, situação atual, metas e resultados. Para exemplificar, trazemos uma frase que se repete três vezes em tópicos distintos: "Aumentar em $10 \%$ o número de crianças alcançando desenvolvimento infantil adequado segundo a Organização Mundial da Saúde até 2020". Essa frase vai aparecer no tópico 2, "Sumário das Propostas de Governo" (p.5); num item do tópico 3.2.1, "Metas"; no tópico 3.2, "Alto Valor Humano: Equidade de Oportunidades e Cidadania" (p. 11); e no "Resumo das Metas" (p. 103). ${ }^{8}$

Nos demais programas dos candidatos, o termo criança tem uma incidência entre duas e oito vezes. A criança aparece predominantemente relacionada com as áreas da Educação, Saúde e Assistência, tratada, quase na totalidade, como sujeito em desenvolvimento e objeto da Pedagogia ou, ainda, como vulnerável (deficiente, pobre, vítima de exploração e abuso), objeto da assistência.

Reproduzimos a seguir alguns fragmentos encontrados nas propostas:

Criar programas especializados, articulados a projetos e ações na saúde e na assistência social, para o desenvolvimento afetivo e cognitivo da criança e da família, desde antes do parto, até o terceiro ano de vida, considerando o fato de a primeira infância ser absolutamente decisiva para o desenvolvimento cognitivo e emocional da criança (Coligação Todo Rio, ${ }^{9} 2016$, p. 3).

Qualificar e fortalecer a rede de proteção social e as ações de atenção especializadas de atendimento, considerando os diversos segmentos que compõem os grupos vulneráveis, como crianças e adolescentes, idosos, pessoas com deficiência, pessoas com questões de saúde mental, pessoas com dependência química e outros (Coligação Todo Rio, 2016, p.4).

\footnotetext{
${ }_{6}$ Proposta do Partido Novo, da candidata à prefeita Carmen Pires Migueles.

7 Trata-se do documento mais extenso, uma vez que foi uma apropriação do Plano Estratégico "Visão Rio 500", contratado e custeado pelo município, e do qual o candidato Pedro Paulo, que integrava a gestão do então prefeito Eduardo Paes, foi coordenador (Consultor Jurídico, 2017). Essa situação resultou na "[...] condenação por abuso de poder político e econômico e a inelegibilidade por oito anos do ex-prefeito do Rio, Eduardo Paes (PMDB), e do deputado federal Pedro Paulo (PMDB-RJ)" (O GLOBO, 2018).

8 Proposta "\#Chega Junto", do candidato Pedro Paulo, da coligação "Juntos pelo Rio".

9 Programa da candidatura de Alessandro Molon e Roberto Anderson, Coligação Todo Rio - Rede Sustentabilidade (Rede), Partido Verde (PV), Partido Pátria Livre (PPL).
}

Nesses fragmentos acima, o discurso dirigido para a infância é no sentido da tutela, como objeto de ações da saúde e assistência. $\mathrm{O}$ objetivo é proteger e preparar a criança para o futuro, para que ela se desenvolva cognitiva e emocionalmente e venha a ser um sujeito saudável. Essa perspectiva também é recorrente quando se apresentam ações no campo educacional destinadas às crianças, como verificamos nos trechos abaixo:

A educação infantil atual, base para o aprendizado, utiliza a lógica de ocupação da criança e não de estímulo para sua boa formação. Nossa proposta é ampliar a política de ensino por tempo integral e buscar a universalização da educação infantil ( 0 a 5 anos $)$ com foco no estímulo cognitivo desde a primeira infância (0 a 3 anos) (Coligação Juntos Pelo Rio! ${ }^{10}$, 2016, p. 6).

Reforma pedagógica nas creches municipais, em parceria público-privado, para aplicar as mais modernas medidas de desenvolvimento intelectual de criança de 0 a 6 anos de idade, além do aumento do período de funcionamento, das 7 às 19 horas (O Rio precisa de Força para Mudar ${ }^{11}, 2016$, p. 6).

[...] o maior desenvolvimento da criança se dá no período de 0 a 6 anos, onde ela deve ser educada nas mais modernas práticas[...] (O Rio precisa de Força para Mudar, 2016, p.6).

As ações educacionais não são formuladas no sentido das experiências presentes das crianças, respeitando seu direito de conviver e compartilhar com outras crianças e com outros espaços para além do ambiente familiar, e também sua condição de sujeito de cultura. Além disso, a esfera da educação é confundida com a de assistência, ao propor que as creches municipais funcionem das 7 às 19 horas, retomando a concepção de abrigos:

Situação Atual: Desde 2009, a Prefeitura do Rio de Janeiro optou por investir na primeira infância, buscando disponibilizar serviços para crianças de 0 a 5 anos e 11 meses e suas famílias que permitam equiparar oportunidades de desenvolvimento infantil e prevenir algumas das causas estruturais da pobreza (3.2.2.1. Primeira Infância Carioca) (\#Chega Junto, 2016, p. 13).

Aumentar em 10\% o número de crianças alcançando desenvolvimento infantil adequado segundo a Organização Mundial da Saúde até 2020 (\#Chega Junto, 2016, p. 102).

Estabelecer, no primeiro ano de governo, uma parceria com o Ministério Público e com o Conselho Tutelar

\footnotetext{
${ }^{10}$ Proposta do candidato Índio da Costa, do PSD, da coligação Juntos pelo Carioca - Partido Social Democrático (PSD), Partido Socialista Brasileiro (PSB), Partido da Mulher Brasileira (PMB).

${ }^{11}$ Proposta do candidato Flavio Bolsonaro, do PSC, da coligação O Rio Precisa de Força para Mudar, Partido Social Cristão (PSC), Partido Republicano Progressista (PRP).
} 
para combater a exploração de crianças nas ruas pelos próprios pais ou por outros adultos (Segurança e Guarda Municipal) (Por um Rio Mais Humano ${ }^{12}$, 2016, p.5).

Fora a incidência maciçamente nas áreas de Saúde, Educação e Assistência, parte dessas propostas está associada também à área de Segurança, como o fragmento acima da proposta "Por um Rio mais Humano", do candidato Marcelo Crivella. Outras áreas também identificadas foram Esporte e Cultura, mas, mesmo assim, nesses textos, a criança se reduz a seu "ofício de aluno", visto que tais ações estão associadas à escola e à tarefa de aprender e formar-se. A seguir, trazemos fragmentos da proposta \#Chega Junto, do candidato Pedro Paulo:

Integração do esporte com o projeto pedagógico da educação municipal: Estudos apontam a importância de iniciar uma vida fisicamente ativa já na infância para incorporação de hábitos saudáveis e melhor desenvolvimento motor e social. A educação física nas escolas é o meio mais eficiente e inclusivo de agregar à vida de todas as crianças - independente de sua capacidade ou deficiência, sexo, idade, cultura, raça/etnia, religião ou classe social - as habilidades, atitudes, valores, o conhecimento e entendimento das habilidades, atitudes e valores para participação em atividades físicas e esportivas ao longo da vida.

- Intensificar programas esportivos para crianças no contra turno (sic) escolar;

- Criar estratégias para lidar com a evasão escolar, envolvendo a família com atividades físicas como uma ferramenta de motivação e exemplo para a criança e o jovem [ESPORTES E LAZER] (Juntos pelo Rio, 2016, p. 33-34).

$\mathrm{Na}$ mesma proposta, a relação da criança com a área de Cultura vai aparecer num subitem denominado "Cultura de Paz". Nesse caso, associa-se à escola, mas também à Segurança.

Situação Atual: Em uma Cidade onde crianças ainda são expostas a diferentes formas de violência, promover um ambiente escolar voltado para a paz é um grande desafio. O espaço escolar, embora não seja suficiente, é um dos que melhor pode colaborar para a consolidação de uma cultura de paz, por meio do desenvolvimento de habilidades e competências socioemocionais, do fortalecimento da cidadania, do desenvolvimento de estratégias de resolução de conflitos e da articulação da escola com território em que está inserida (3.2.2.9. Cultura de Paz) (\#Chega Junto, 2016, p. 20).

\footnotetext{
${ }^{12}$ Proposta do candidato Marcelo Crivella (PRB).
}

A criança que predomina nos discursos produzidos nas campanhas eleitorais para a prefeitura do Rio de Janeiro é concebida como incompleta e objeto da Pedagogia. É vista como uma pessoa a ser "preparada para a vida", sujeito de aprendizagem e de desenvolvimento afetivocognitivo, motor e social. Seu lugar é na escola ou, quando em outro espaço, que este esteja a serviço da escolarização. Uma escolarização com forte conteúdo disciplinador, modelador e pacificador, mas não no sentido de construção de pactos e enfrentamento das desigualdades e injustiças que produzem e se sustentam numa sociedade e num Estado violento. A "consolidação de uma cultura de paz" é apresentada como se fosse uma questão própria dos "territórios" em que as escolas estão inseridas.

Mas é possível falar de "cultura de paz" quando os "direitos fundamentais inerentes à pessoa humana" são cotidianamente violados pelo Estado? Como expresso na canção do grupo O Rappa, "[...] paz sem voz [...] Não é paz, é medo". ${ }^{13}$ É preciso lembrar que, na cidade do Rio de Janeiro, o índice de morte por arma de fogo é alto. Dos Estados brasileiros é a capital que tem a polícia que mais mata e a que mais morre (EL PAÍS, 2017). Mas é preciso lembrar que as crianças também são grandes vítimas desse cenário, ao morrerem ou serem feridas pelas chamadas balas perdidas. Isso sem contar com a condição de desemprego e trabalho precário em que vivem seus familiares, com a falta de saneamento básico, saúde pública, transporte e moradia para as camadas populares.

A condição de sujeito sem voz e em falta, além de transformar a criança em objeto da Pedagogia e fixá-la na escola (como as borboletas de colecionadores na alegoria de Montessori), também traz a figura do "carente", vulnerável, que precisa mais do que proteção; precisa de tutela:

Medidas de combate à exploração e ao turismo sexual de mulheres, crianças, adolescentes e jovens (Rio em Comum ${ }^{14}, 2016$, p. 8).

Implantar equipes de vigilância, mediação e tratamento voltadas para as vítimas de exploração sexual infantil (Juntos pelo Rio!, 2016, p.31).

Implementação do programa "Escola sem Partido" (neutralidade político-partidária em sala de aula), e proibição de conteúdos com temática ideológica de gênero, evitando a antecipação da sexualidade de crianças (O Rio Precisa de Força para Mudar, 2016, p.7).

\footnotetext{
${ }^{13}$ Canção Minha alma, de autoria de Alexandre Monte de Menezes, Lauro José de Farias, Marcelo de Campos Lobato, Marcelo Falcão Custódio, Marcelo Fontes do Nascimento, Vi Santana, gravada pelo Grupo O Rappa. Disponível em: <https://www.youtube.com/watch?v=dixEvTzhlaY $>$. Acesso em: 25 mar. 2018.

${ }^{14}$ Proposta da candidata Jandira Feghali (Partido Comunista do Brasil PCdoB), da coligação com o Partido dos Trabalhadores (PT).
} 
É fato que grande parte da infância carioca está submetida a precárias condições de vida, mas temos que reconhecer que a perspectiva de incompletude e vulnerabilidade da criança também está associada à sua subordinação à figura materna e ao trabalho feminino, de modo totalmente esvaziado da sua condição de sujeito. A criança é um objeto que qualifica a mulher - a mulhermãe; uma mulher sobrecarregada. Ela representa um problema para a vida das mulheres, e toda ação a ela destinada será para beneficiar as mulheres - estas, sim, sujeitos de direitos:

\begin{abstract}
Aumentar o número de creches e ampliar seu atendimento para o horário da noite, visando atender as crianças cujas mães ou responsáveis necessitem trabalhar ou estudar nesse período, assim como estender o horário de atendimento e guarda às crianças do ensino fundamental em igual situação, otimizando o uso noturno das nossas escolas já existentes (Rio em Comum, 2016, p. 19).

Falar de educação também nos remete às creches públicas, beneficiando as mães cariocas e suas famílias no atendimento diário de suas crianças. É preciso uma estrutura concreta do poder público municipal para que seus filhos tenham atenção integral, com alimentação e ensino de qualidade (Rio em Comum, 2016, p. 2).
\end{abstract}

O sentido de esvaziamento da condição de sujeito em relação à criança também verificamos num tópico referente à participação popular, em que a criança (assim como o adolescente) aparece como um tema dentre outros, como Saúde, Educação, Assistência Social e Meio Ambiente. Destacamos, ainda, nesse fragmento, o seu final, em que se faz menção a populações específicas, como comunidade LGBT, grupos étnico-raciais, povo de terreiro, povos indígenas, pessoas idosas e pessoas com deficiência, mas as crianças e os adolescentes permanecem invisíveis, como podemos constatar a seguir:

O planejamento, o controle social e a gestão de políticas públicas passarão a ser influenciados por esses diálogos sociais ocorridos nas conferências temáticas, levando à construção de um modelo institucional com a participação dos(as) usuários(as) dos serviços públicos. As conferências possibilitam o debate amplo de temas, desde os assuntos tradicionais, como saúde, educação, assistência social, meio ambiente, criança e adolescente, até novas necessidades de elaboração de políticas específicas para determinados setores sociais, como as populações de orientação sexual lésbica, gay, bissexual, travesti e transexual (LGBT), de promoção de igualdade racial, do povo de terreiro, dos povos indígenas, das pessoas idosas e das pessoas com deficiência (Rio em Comum, 2016, p.4).
A constatação da presença de criança definida pela negatividade - irracional, carente, vulnerável - era esperada quando iniciamos nossas leituras dos programas, não causando surpresa. Entretanto, tínhamos uma expectativa de encontrar uma criança potente e sujeito de direitos com mais frequência. De fato, ela vai aparecer apenas em dois programas e em duas passagens, como reproduzimos a seguir:

Todo trabalhador e trabalhadora, todos os jovens e todas as crianças devem ter assegurado o seu direito à moradia $[\ldots]\left(\mathrm{PSTU}^{15}, \mathrm{p} .4\right)$.

Criar, reinstituir e/ou fortalecer os conselhos municipais de políticas públicas, em especial, os conselhos de Defesa dos Direitos Humanos (CMDDH), de Juventude (COMJU), da Mulher (CMDM), dos Direitos da População LGBT (CMLGBT), de Defesa dos Direitos do Negro (COMDEDINE), de Defesa da Criança e do Adolescente (CMDCA), dos Direitos da Pessoa Idosa (CMDPI) e da Defesa dos Direitos das Pessoas com Deficiência (COMDEF), dando-lhes estrutura e capacidade de avaliação, consulta e deliberação sobre as políticas públicas de promoção, garantia e defesa dos direitos e liberdades dessas populações (Mudar é Possível ${ }^{16}, 2016$, p. 6).

Aqui observamos emergir uma concepção de criança sujeito de direito, entretanto cabe refletir sobre a "substância dos direitos da criança", como propõem Sarmento e Pinto (1997). A condição de sujeito ativo e propositivo, participante, não se evidenciou em nenhum dos documentos e continua sendo um grande desafio para pensarmos as políticas públicas e a relação cidade e infância. Os referidos autores identificam três tipos ou substâncias de direitos, dos quais os dois primeiros são proclamados nos discursos recorrentes:

[...] A tradicional distinção entre direitos de protecção (do nome, da identidade, da pertença a uma nacionalidade, contra a discriminação, os maus-tratos e a violência dos adultos, etc.), de provisão (de alimento, de habitação, de condições de saúde e assistência, de educação, etc.) e de participação (na decisão relativa à sua própria vida e à direção das instituições em que actua), constitui uma estimulante operação analítica. Ela permite, quando aplicada à investigação do estado de realização dos direitos, comprovar, por exemplo, que entre os três $\mathbf{p}$, aquele sobre o qual menos progressos se verificaram na construção das políticas e na organização e gestão das instituições para a infância (e, em particular, nas escolas - cf. Jeffs, 1995) é o da participação (SARMENTO; PINTO, 1997, p. 19, grifo dos autores).

\footnotetext{
${ }^{15}$ Proposta do candidato Cyro Garcia, do Partido Socialista dos Trabalhadores Unificado (PSTU), sem coligação.

${ }^{16}$ Proposta do candidato Marcelo Freixo (PSOL), em coligação com o Partido Comunista Brasileiro (PCB).
} 


\section{A título de CONClusão}

A análise dos programas evidenciou o quanto ainda é necessário investir na produção de discurso que afirme o lugar das crianças como sujeitos de direitos. Direitos fundamentais à pessoa que, mesmo sem desprezar a relevância da educação e da escola na vida das crianças, não se configuram na única esfera e direito de suas vidas. É preciso reconhecer que as crianças também demandam outros direitos (de expressão, de liberdade, de organização, e não só de proteção e formação), manifestam, atuam e se interessam por diferentes esferas da cultura, da arte e da política. O que representa um desafio para todos nós que atuamos no campo de investigação e trabalho com crianças e infâncias, não só por aquilo que as beneficiará, mas também pelo fortalecimento de toda a sociedade. Isso porque a "[...] invisibilidade de determinados tipos de sujeitos no processo de materialização da cidade é que a esvazia da dimensão pública, dando-lhe uma configuração privada [...]" (ARAÚJO, 2011, p. 137).

Assim, propomos, juntamente com as crianças, indagar sobre nossos sonhos e desejos. Que tipo de cidade queremos? Reivindicar o direito à cidade, que "[...] está longe da liberdade individual de acesso a recursos urbanos: é o direito de mudar a nós mesmos pela mudança na cidade" (HARVEY, 2012, p. 74). Nesse processo, é preciso reconhecer as crianças como atores sociais parceiros nessa empreitada pela mudança.

Das conversas de crianças, obscuras ao adulto Compreendo sem dificuldade o sentido oculto.

(GIANNI RODARI)

\section{REFERÊNCIAS}

ARAÚJO, Vania Carvalho de. A cidade como espaço público de educação e de afirmação da cidadania: a experiência de Vitória/ ES, Brasil. Revista Brasileira de Política e Administração da Educação (RBPAE) (Porto Alegre: Anpae), v. 27, n. 1, p. 135-148, jan./abr. 2011.

ARENHART, Deise. Culturas infantis e desigualdades sociais. Petrópolis/RJ: Vozes, 2016.

BENJAMIN, Walter. Reflexões sobre a criança, o brinquedo e a educação. São Paulo: Ed. 34, 2009.

BENJAMIN, Walter. A hora das crianças: narrativas radiofônicas. Tradução Aldo Medeiros. Rio de Janeiro: NAU Editora, 2015.

BRASIL. Constituição (1988). Constituição [da] República Federativa do Brasil. Brasília: Senado Federal, 1988. Disponível em: <http://www.senado.gov.br/sf/legislacao/ const/>. Acesso em: 13 abr. 2014.

BRASIL. Lei no 8.069, de 13 de julho de 1990. Dispõe sobre o Estatuto da Criança e do Adolescente e dá outras providências. Disponível em: <http://www.planalto.gov.br/ccivil 03/leis/ L8069.htm>. Acesso em: 4 maio 2017.
BRASIL. Decreto no 99.710, de 21 de novembro de 1990. Promulga a Convenção sobre os Direitos da Criança. Disponível em: <http://www.planalto.gov.br/ccivil 03/decreto/1990-1994/ d99710.htm>. Acesso em: 4 maio 2017.

CONSULTOR JURÍDICO. TRE-RJ deixa Eduardo Paes e Pedro Paulo inelegíveis por oito anos. 11 de dezembro de 2017. Disponível em: <https://www.conjur.com.br/2017-dez-11/trerj-deixa-eduardo-paes-pedro-paulo inelegiveis-oito-anos $>$. Acesso em: 19 abr. 2018.

EL PAIS. No Rio, a polícia que mais mata é também a que mais morre. Reportagem de María Martín. 10 abr. 2017. Disponível em: <https://brasil.elpais.com/brasil/2017/04/04/ politica/1491332481_132999.html>. Acesso em: 16 abr. 2018.

FLORESTAN, Fernandes. As "Trocinhas" do Bom Retiro: contribuição ao estudo folclórico e sociológico da cultura e dos grupos infantis. Pro-Posições, v. 15, n. 1, p. 229-250, jan./abr. 2004.

FREINET, Elise. O intinerário de Célestin Freinet: a livre expressão na pedagogia Freinet. Tradução de Priscila de Siqueira. Rio de Janeiro: Francisco Alves, 1979.

HARVEY, David. O direito à cidade. Lutas Sociais, São Paulo, n. 29, p. 73-89, jul./dez. 2012. Disponível em: $<$ https://revistas. pucsp.br/index.php/ls/article/view/18497/13692>. Acesso em: 4 maio. 2017.

SARMENTO, Manuel Jacinto. Visibilidade social e estudo da infância. In: VASCONCELOS, Vera Maria Ramos de; SARMENTO, Manuel Jacinto (Org.). Infâncias (in)visíveis. Araraquara: J\&M Martins, 2007.

SARMENTO, Manuel Jacinto; PINTO, Manuel. As crianças e a infância: definindo conceitos, delimitando o campo. In: PINTO, Manuel; SARMENTO, Manuel Jacinto (Org.). As crianças: contextos e identidades. Braga: Bezerra, 1997. p. 9-30.

TONUCCI, Francesco. Com olhos de criança. Tradução Patrícia Chittoni Ramos. Porto Alegre: Artes Médicas, 1997.

\section{Propostas de governo}

\#CHEGA JUNTO. Plano de governo. Prefeito - Pedro Paulo. Coligação \#Chega Junto. Partido Movimento Democrático Brasileiro (PMDB) - Partido Democrático Trabalhista (PDT) - Partido Progressista (PP) - Partido Trabalhista Brasileiro (PTB) - Partido Social Liberal (PSL) - Solidariedade (SD) Democratas (DEM) - Partido Republicano da Ordem Social (PROS) - Partido Humanista da Solidariedade (PHS) - Partido da Mobilização Nacional (PMN) - Partido Ecológico Nacional (PEN) - Partido Social Democrata Cristão (PSDC) - Partido Trabalhista Cristão (PTC) - Partido Trabalhista do Brasil (PT do B) - Partido Renovador Trabalhista Brasileiro (PRTB). Rio de Janeiro/RJ, 2016, p. 110.

COLIGAÇÃO JUNTOS PELO RIO! Plano de governo: 2017-2020. Prefeito - Índio; vice - Hugo Leal. Partido Social Democrático (PSD) - Partido Socialista Brasileiro (PSB) Partido da Mulher Brasileira (PMB). Rio de Janeiro/RJ, 2016. p. 43 .

COLIGAÇÃO MUDAR É POSSÍVEL. Programa de governo. Prefeito - Marcelo Freixo; vice - Luciana Boiteux. Partido Socialismo e Liberdade (PSOL) - Partido Comunista Brasileiro (PCB). Rio de Janeiro/RJ, 2016. p. 67. 
COLIGAÇÃO RIO DE OPORTUNIDADES E DIREITOS. Plano de Governo: 2017-2020. Prefeito - Osório; vice Aspásia. Partido da Social Democracia Brasileira (PSDB) Partido Popular Socialista (PPS) - Partido Social Democrata Cristão (PSDC). Rio de Janeiro/RJ, 2016. p. 36.

COLIGAÇÃO TODO RIO. Programa para a candidatura de Alessandro Molon e Roberto Anderson. Rede Sustentabilidade (Rede) - Partido Verde (PV) - Partido Pátria Livre (PPL). Rio de Janeiro/RJ, 2016. p. 6.

O RIO PRECISA DE FORÇA PARA MUDAR. Proposta. Flavio Bolsonaro. Coligação Partido Social Cristão (PSC) Partido Republicano Progressista (PRP). Rio de Janeiro/RJ, 2016. p. 15.

PARTIDO DA CAUSA OPERÁRIA (PCO). Programa do PCO para as eleições municipais 2016. Thelma Bastos. Rio de Janeiro/RJ, 2016. p. 5.

PARTIDO NOVO. Propostas. Carmen Pires Migueles; Tomás Pelosi Filho. Rio de Janeiro/RJ, 2016. p. 2.
PARTIDO SOCIALISTA DOS TRABALHADORES UNIFICADO (PSTU). Programa para as eleições. Rio de Janeiro/ RJ, 2016. p. 10 .

POR UM RIO MAIS HUMANO. Programa de governo. Crivella Prefeito 2016. Partido Republicano Brasileiro (PRB) - Partido da República (PR) - Partido Trabalhista Nacional (PTN). Rio de Janeiro/RJ, 2016. p. 8.

RIO EM COMUM. Plano de governo. Jandira Feghali. Coligação Partido Comunista do Brasil (PCdoB) - Partido dos Trabalhadores (PT). Rio de Janeiro/RJ, 2016. p. 36.

Recebido em 08.05.2018

Aprovado em 09.07.2018

Endereço para correspondência:

Universidade do Estado do Rio de Janeiro

Programa de Pós-Graduação em Educação

Rua São Francisco Xavier, 524 - Grupo 12.037-F

20550-013 Rio de Janeiro, RJ, Brasil 